\title{
Do reciprocal relationships between academic workload and self-regulated learning predict medical freshmen's achievement? A longitudinal study on the educational transition from secondary school to medical school
}

\author{
Joselina Barbosa ${ }^{1,2,3}$ - Álvaro Silva ${ }^{3}$ Maria Amélia Ferreira ${ }^{1,2} \cdot$ Milton Severo $^{1,4}$
}

Received: 14 November 2017 / Accepted: 5 April 2018

(C) Springer Science+Business Media B.V., part of Springer Nature 2018

\begin{abstract}
One of the most important factors that makes the transition from secondary school to medical school challenging is the inability to put in the study time that a medical school curriculum demands. The implementation of regulated learning is essential for students to cope with medical course environment and succeed. This study aimed to investigate the reciprocal relationships between self-regulated learning skills (SRLS) and academic workload (AW) across secondary school to medical school transition. Freshmen enrolled in medical school $(\mathrm{N}=102)$ completed questionnaires at the beginning and at the end of their academic year, assessing AW (measured as study time hours and perceived workload), SRLS (planning and strategies for learning assessment, motivation and action to learning and self-directedness) and academic achievement. An exploratory factor analysis (EFA) and a longitudinal path analysis were performed. According to the EFA, study time and perceived workload revealed two factors of AW: students who had a high perceived workload also demonstrated increased study time (tandem AW); and those who had a low perceived workload also demonstrated increased study time (inverse AW). Only a longitudinal relationship between SRLS and AW was found in the path analysis: prior selfdirectedness was related to later tandem AW. Moreover, success during the first year of medical school is dependent on exposure to motivation, self-directedness and high study time without overload during secondary school and medical school, and prior academic achievement. By better understanding these relationships, teachers can create conditions that support academic success during the first year medical school.
\end{abstract}

Keywords Study time $\cdot$ Subjective workload $\cdot$ Self-regulated learning skills $\cdot$ Educational transition $\cdot$ Freshmen $\cdot$ Medical school

Joselina Barbosa

joselina@med.up.pt

1 Faculty of Medicine, University of Porto, Porto, Portugal

2 Cardiovascular Research and Development Center, University of Porto, Porto, Portugal

3 Institute of Biomedical Sciences Abel Salazar, University of Porto, Porto, Portugal

4 Institute of Public Health, University of Porto, Porto, Portugal 


\section{Introduction}

Students selected for medical courses in universities are among those ranked at the top. It is often assumed that these students are well prepared for the demands of medical school. However, is it possible for these bright students, who have performed exceptionally in secondary school, to also excel in their first year of medical school? Medicine is a challenging and demanding course and students must learn how to succeed under a completely different set of rules. In most cases, students adapt to the new environment, but some find it difficult to fill the gap between expectations and reality (Mehdinezhad 2011).

One of the most important factors that makes the transition from secondary school to medical school challenging is the inability to put in the study time that a medical school curriculum demands. The complexity and volume of the material to be learned and the pace of the medical curriculum leads students to spend most of their time studying (Guthrie et al. 1995; Smith et al. 2007; Gomathi et al. 2012; Torenbeek et al. 2010).

In general, the time devoted to study has been recognized as a major factor in the teaching and learning environment, which influences the quality of learning (Kyndt et al. 2011; Schmidt et al. 2010). Karjalainen et al. (2006) noted that, 'even an infinite amount of time does not guarantee learning, although the existence of time is an essential condition to learning'. Success is maximised if the study time is extended to the maximum amount needed (Carroll 1963); nevertheless, many medical students struggle with effective time management, and balancing a heavy workload and social life can be especially tough for these students who have been used to the structure of the secondary school education. Likewise, a student experiencing overload is unable to learn effectively and tends to emphasize their efforts on surface learning (Devlin and Gray 2007). Additionally, it can have implications on the students' well-being (Jacobs and Dodd 2003). Work overload and the feeling of being overwhelmed have been identified as a major source of stress and academic burnout in first year medical students (Costa et al. 2012; Guthrie et al. 1995).

Thus, it becomes inevitable for medical students to change their long-held study habits in order to succeed (Krause and Coates 2008; Brint and Cantwell 2010). The use of strategic selection and implementation of regulated learning is therefore, the key for students to adapt to such a demanding learning environment (Demirören et al. 2016). Previous studies have shown that students must use self-regulated learning skills to cope with the medical course environment and its vast content (Artino et al. 2012; Jouhari et al. 2015). Self-regulated learning skills (SRLS) had been associated with student grades (West and Sadoski 2011), clinical skills (Kassab et al. 2015) and lower depression in medical course (Sandars and Cleary 2011). Self-regulated learners plan and set goals, delineate learning strategies, monitor their progress, and evaluate their results (Zimmerman 2002; Turan et al. 2009). Zimmerman defined self-regulated learning as the degree to which students are 'metacognitively, motivationally, and behaviorally active participants of their own learning process' (Zimmerman 1989; Zimmerman and Schunk 2008). Self-regulated learners are supposed to understand the impact of the environment on them and know how to constantly enhance their skills (Zimmerman and Schunk 2001).

Thus, we hypothesize that freshman medical students who develop self-regulated learning skills (SRLS) would be less likely to struggle with high study time and consequently, have a higher academic achievement. In turn, it may also be possible that a high study time results in favourable self-regulated learning and, consequently, a higher academic achievement. 
Against this background, our main aim was to investigate the reciprocal relationships between SRLS and academic workload in the educational transition from secondary school to medical school and to explore whether these relationships have an effect on academic achievement at first year of medical school.

Academic workload might be thought of as playing two roles: ideally, high study time will generate greater learning. However, more study time may result in increased overload due to poor study technique. In this context, we combine both objective (as measured by the time devoted to study) and subjective (as measured by the demands perceived by students) assessments to measure academic workload. This will assess the study time and perceived workload associated with undertaking a first-year medical course. We used the self-regulated learning perception scale that includes four skills domains: motivation and action toward learning, planning and goal setting, strategies for learning assessment, and lack of self-directedness (Turan et al. 2009).

\section{Methods}

\section{Educational context}

This study was conducted in a public medical school in the north of Portugal. New students are admitted to the school based on their upper secondary school's grade and the national exams grade in biology and geology, physics and chemistry and mathematics. The medical course spans 6 years that are divided into pre-clinical and clinical stages during the first and last 3 years, respectively. Time devoted to study constituted about two-thirds of the total number of working hours allocated to the curriculum. The new curricular plan-which started in 2013/2014 - has introduced an integrated organization, system and case-based design, and a longitudinal approach of imagiology, therapeutics, and special pathology within clinical subjects. The ultimate goal was to increase integration between topics.

\section{Participants and procedures}

Participants of this study comprised students enrolled in the first year of the medical course. A longitudinal design was used to collect data for identical variables at Time 1 (T1) and Time 2 (T2). Data were collected in September 2014 (after entry to medical school) and September 2015 (after the first year of the medical course) during lessons, using the same questionnaires. This study was approved by the Faculty of Medicine of the University of Porto/São João Hospital Ethics Committee. Participation was voluntary and data confidentiality was guaranteed. At T1, 120 medical freshmen completed the survey; 102 students (43\% of those enrolled) with a mean age of 18 years $(S D=1.4)$ completed the follow-up measurement at $\mathrm{T} 2$; of those, $63.7 \%$ were female. There were no statistically significant differences in gender or age between those who completed and those who did not complete the survey (data not shown).

\section{Measures}

\section{Covariates}

Participants' sex and academic achievement at T1 and T2 were reported. At T1, the academic achievement comprised the average grade for admission to medical school calculated 
according to (a) $50 \%$ of the final grade in upper secondary school, and (b) $50 \%$ of the grade for national exams in biology and geology, physics and chemistry, and mathematics (distributed evenly). At T2, academic achievement comprised the average grade scored during the first year.

\section{Subjective workload}

Two scales were developed to measure subjective workload based on previous literatures. At both T1 and T2, students completed the Appropriate Workload Scale (AWS) from the Course Experience Questionnaire (CEQ) (Ramsden 1991), and the simple unweighted version of the NASA Task Load Index (NASA-TLX) (Beyers et al. 1989). The CEQ is an instrument for course evaluation in higher education. The AWS includes five items to measure respondents' perceptions of the appropriateness of their respective program's workload, using a 5-point Likert scale ranging from 'definitely disagree' to 'definitely agree'. The item 'It was generally given enough time to understand the things I had to learn' was reversed. Higher scores indicated a greater subjective workload.

The NASA-TLX is a wide-ranging scale used in several contexts to identify six possible workload sources divided into two categories: demands placed on an individual (i.e. mental, physical, and temporal demands) and a task's interaction with an individual (i.e. effort, frustration, and performance). It comprises six items on a 20-point scale. Overall subjective workload is represented by a combination of the six dimensions and higher scores reflected a greater subjective workload.

The AWS is extracted from a larger validated questionnaire which examines student experience in depth. In turn, although NASA-TLX has been used in the context of higher education to investigate the overall workload (Atalay et al. 2016; Kurata et al. 2015), it is usually used to measure the work overload after completion of a task. Therefore, we tried to establish the reliability and validity of these scales in our context. Cronbach's alpha and omega coefficients were used to evaluate the internal consistency of the scales. Construct validity was tested by factor analysis.

The internal consistency reliabilities of the AWS subscale with Cronbach's alpha were 0.6 and 0.8 and with omega coefficient were 0.7 and 0.8 at T1 and T2, respectively. To increase the NASA-TLX's internal consistency, the item concerning performance (i.e. How satisfied were you with your performance?) was removed from the analysis. Despite the probable work overload, the fact that these students have successfully entered the medical course causes them to be satisfied with their performance, at least in the first year of medical school. The NASA-TLX's internal consistency reliabilities with Cronbach's alpha were subsequently 0.7 and 0.6 and with omega coefficient 0.8 and 0.8 at $\mathrm{T} 1$ and $\mathrm{T} 2$, respectively. It suggests that omega coefficient significantly improve the estimation level (Revelle and Zinbarg 2009). Exploratory factor analysis showed that the two scales had good structure validity (except the item concerning performance) ("Appendix 1"). The NASA-TLX was used without the performance item in subsequent analysis.

\section{Study time}

The time devoted to study was estimated using a retrospective self-study frequency questionnaire that asked students to record their frequency of study throughout the academic year (including mean hours of study on a given day) (Barbosa et al. 2016). This was achieved through two questions: (1) 'How often did you study outside the classroom for 
learning purposes, whether for class assignments, group work, or studying for an examination?', and (2) 'On the days that you studied, how many hours did you study on average?' For the first question, the response options were listed on an eight-point scale (never, once or less each month, two to three times each month, once a week, twice a week, three to four times per week, five times per week, six to seven times per week). Since students' study behaviours changed during examination periods, these questions were asked during both normal periods and periods of assessment (Kerdijk et al. 2015). Reported study hours/week was calculated using the selected frequency category (converted into mean times per week) and multiplied by the number of study hours on a given day.

\section{Self-regulated learning skills}

At both time points, students completed the self-regulated learning perception scale (SRLPS) (Turan et al. 2009), a self-report measure of self-regulated learning validated for medical students. The SRLPS included four domains: motivation and action to learning (seven items), planning and goal setting (eight items), strategies for learning assessment (nineteen items), and lack of self-directedness (seven items). Item responses were answered on a five-point scale ranging from 'strongly disagree' to 'strongly agree'. The internal consistency for SRLPS with Cronbach's alpha was 0.9 and with omega coefficient was 0.9 at $\mathrm{T} 1$ and $\mathrm{T} 2$, respectively.

\section{Data analysis}

To derive patterns that could be used to characterise student academic workload (study time and subjective workload) and student SRLS, two exploratory factor analyses (EFA) were performed. The first used subjective workload (AWS and NASA-TLX scales) and study time during classes and assessment periods at both time points; the second used all SLRPS items, also at both time points. Loadings with a magnitude of at least $10.30 \mathrm{l}$ were considered. The number of dimensions for each scale was estimated using optimal coordinates and Kaiser's criterion (eigenvalues $>1$ ). Standardized factor scores produced by the exploratory factor analysis were used in subsequent analyses.

For the preliminary analysis, multiple linear regression analyses were performed to examine the cross-sectional (each T1 variable with all other T1 variables and each T2 variable with all other $\mathrm{T} 2$ variables) and longitudinal (each $\mathrm{T} 2$ variable with all $\mathrm{T} 1$ variables) relationships between academic workload, SRLS, and academic achievement. Backward stepwise selection was used during the exploratory stages of model building to identify a useful subset of predictors until only factors with $p<0.10$ remained.

Path analyses were used to examine how academic workload and SRLS relate with academic achievement. Due to the model's exploratory nature, we inspected the modification indices to determine whether adding a new path would improve the model's overall fit. To evaluate the goodness-of-fit, the Chi square test and goodness-of-fit indices were considered. A non-significant Chi square value indicated a good fit for the model; nevertheless, for a small sample size the index was sensitive (Bentler 1990). Following the advice of Hu and Bentler, the comparative fit index recommended by the global goodness of fit (CFI), when $N<250$ was used (Hu and Bentler 1999). Cut-offs for acceptable model fit were set at $>0.90$ for CFI (Hu and Bentler 1999). The fit of models with missing data was assessed using the maximum likelihood estimation method, which provides unbiased estimates and standard errors when random data are missing (Enders 2010). Standardized betas ( $\beta$ ) are 
presented for each model. Data analysis was performed using the $\mathrm{R}$ integrated software suite.

\section{Results}

\section{EFA}

Exploratory factor analysis with AWS, NASA-TLX, study time during classes' period, and study time during periods of assessment indicated that two factors could be assumed at both time points. The percentage of variance explained by each factor was 51 and $24 \%$ at baseline and 45 and $23 \%$ at follow-up. The factor loadings for Factor 1 suggested that students with a high subjective workload devoted high time to study or that those with low subjective workload devoted less time to study. The factor loadings for Factor 2 suggested that students with a low subjective workload devoted a large amount of time to study or, in contrast, those with high subjective workload dedicated less time to study. The Factor 1 was labelled tandem academic workload since both variables moved in tandem, whereas the second was labelled inverse academic workload since one variable increased as the other decreased (see "Appendix 2").

Exploratory factor analysis of the SRLPS items at each measurement occasion indicated that the optimal coordinates defined three factors at both time points. The factor loadings for Factor 1 comprised two original domains (i.e. 'planning and goal setting' and 'strategies for learning assessment'); hence, Factor 1 was labelled planning and strategies for learning assessment.

The factor loadings for Factor 2 measured 'motivation and action to learning'; the factor therefore inherited this descriptor. The factor loadings for Factor 3 measured 'lack of selfdirectedness', and as the factor loadings were negative, this component was labelled selfdirectedness. However, at T1 and T2, both items moved from the original domain (strategies for learning and assessment) to motivation and action to learning ('I search for ways to facilitate learning in new situations', and 'I use my own learning strategies'). Additionally, two more items moved from the original domain to motivation and action to learning during T2 ('I explore other peoples' methods of problem solving', and 'I compare other peoples' problem solving strategies with my own') (see "Appendix 3").

\section{Preliminary analysis}

A cross-sectional analysis that used baseline data (each T1 variable with all other T1 variables with Backward stepwise selection) revealed that tandem academic workload was positively associated with planning and strategies for learning assessment. Additionally, inverse academic workload was positively associated with academic achievement. At follow-up (each T2 variable with all T2 variables with backward stepwise selection), inverse academic workload, motivation and action to learning, and self-directedness were positively associated with academic achievement (see Table 1).

The longitudinal analysis (each T2 variable with all T1 variables with backward stepwise selection) revealed that all variables had a significant stable effect over time. Regarding the cross-lagged effects, only a positive significant association was observed from selfdirectedness at T1 to tandem academic workload at T2 (see Table 2). 


\section{Path analysis}

The initial path model was created to reflect relationships arising from the preliminary analysis. The model fit was inadequate, and the modification indices indicated that adding a path from baseline motivation and action to learning to follow-up academic achievement would improve the model fit significantly. Figure 1 shows the path model linking tandem and inverse academic workload, planning and strategies for learning assessment, motivation and action to learning, and self-directedness in academic achievement. The model possessed a comparative fit index (CFI) of 1.000, and a root mean square error of approximation (RMSEA) of 0.000, thereby demonstrating goodness of fit. For a sensitive analysis, we assessed the model's fit according to gender where all path directions were identical to the final model (data not shown).

As can be seen in Fig. 1, all examined variables exhibited stable effects over time.

Two significant cross-lagged associations were found. We observed a significant relationship between self-directedness at secondary school and the later tandem academic workload $(\beta=-0.20 ; p=0.016)$. However, this relationship does not predict academic achievement. Furthermore, high levels of motivation and action to learning at the secondary level resulted in low academic achievement in medical school $(\beta=-0.23$; $p=0.009$ ).

Table 1 Cross-sectional associations between academic workload, self-regulated learning skills and academic achievement

\begin{tabular}{llc}
\hline & $\beta(95 \%$ CI $)$ & $p$ value \\
\hline $\begin{array}{l}\text { Baseline } \\
\quad \text { Tandem academic workload, T1 }\end{array}$ & & \\
$\quad$ Planning and strategies for learning assessment, T1 & $0.285(0.104 ; 0.465)$ & 0.002 \\
$\quad$ Inverse academic workload, T1 & $0.277(0.053 ; 0.501)$ & 0.016 \\
$\quad$ Academic achievement, T1 & & \\
$\quad$ Academic achievement, T1 & $0.184(0.035 ; 0.332)$ & 0.016 \\
$\quad$ Inverse academic workload, T1 & $0.282(0.103 ; 0.460)$ & 0.002 \\
$\quad$ Planning and strategies for learning assessment, T1 & & \\
$\quad$ Tandem academic workload, T1 & $0.176(0.044 ; 0.307)$ & 0.009 \\
Follow-up & $0.339(0.008 ; 0.669)$ & 0.045 \\
$\quad$ Inverse academic workload, T2 & $0.277(-0.019 ; 0.572)$ & 0.066 \\
$\quad$ Academic achievement, T2 & $0.352(0.057 ; 0.648)$ & 0.057 \\
$\quad$ Academic achievement, T2 & & \\
$\quad$ Inverse academic workload, T2 & & \\
$\quad$ Motivation and action to learning, T2 & $0.151(0.030 ; 0.298)$ & 0.045 \\
$\quad$ Self-directedness, T2 & & \\
$\quad$ Motivation and action to learning, T2 & & \\
$\quad$ Academic achievement, T2 & $0.529(0.158 ; 0.899)$ & 0.006 \\
$\quad$ Self-directedness, T2 &
\end{tabular}

Each linear regression included all variables of same moment with backward selection. There are only presented the significant associations at $p<0.10$ 
Table 2 Longitudinal associations between academic workload, self-regulated learning skills and academic achievement

$\beta(95 \% \mathrm{CI}) \quad p$ value

Tandem academic workload, T2

Tandem academic workload, T1

$0.476(0.267 ; 0.684)$

Self-directedness, T1

$-0.174(-0.353 ; 0.006)$

Inverse academic workload, T2

Inverse academic workload, T1

$0.380(0.184 ; 0.575)$

Planning and strategies for learning assessment, T2

Planning and strategies for learning assessment, T1

$0.369(0.152 ; 0.586)$

Motivation and action to learning, T2

Motivation and action to learning at T1

$0.495(0.289 ; 0.702)$

Self-directedness, T2

Self-directedness, T1

$0.451(0.270 ; 0.632)$

Academic achievement, T2

Academic achievement, T1

$0.567(0.214 ; 0.920)$

0.002

Each linear regression included all variables of $\mathrm{T} 1$ with backward selection. There are only presented the significant associations at $p<0.10$

\section{$\mathrm{X}^{2}(53)=51.19 ; p=0.545 ;$ CFI $=1.000 ;$ RMSEA $=0.000$}

T1

T2

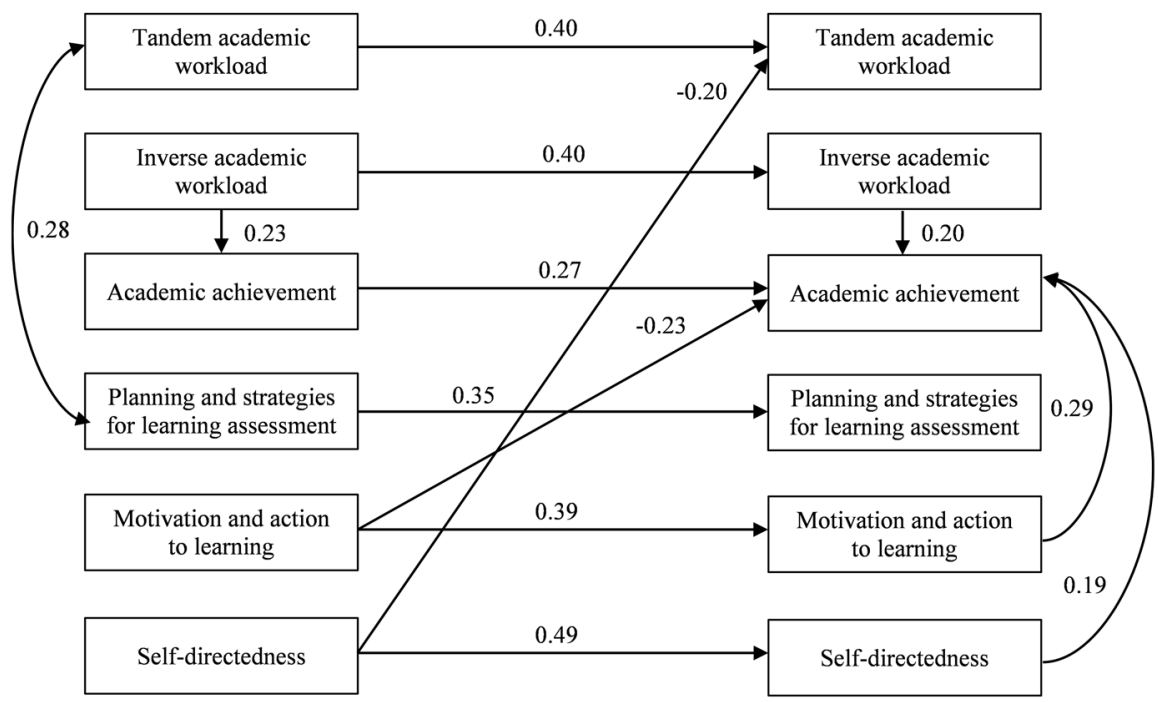

Fig. 1 Path model with standardised estimates. All arrows had significant estimates of at least a 5\% level. A one-way arrow indicates the direct effect of one variable on another; a two-way arrow indicates that variables are correlated without any assumed direct relationship 
Indirect lagged effects were also observed. Inverse academic workload at the secondary level predicted inverse academic workload at medical school $(\beta=0.40 ; p<0.001)$, and, consequently predicted medical school academic achievement $(\beta=0.20 ; p=0.013)$. Motivation and action to learning at the secondary level predicted motivation and action to learning at medical school $(\beta=0.39 ; p<0.001)$, and consequently, predicted medical school academic achievement $(\beta=0.29 ; p=0.001)$. Self-directedness at the secondary level predicted self-directedness at medical school $(\beta=0.49 ; p<0.001)$, and consequently, predicted medical school academic achievement $(\beta=0.19 ; p=0.015)$.

Finally, at secondary school, the tandem academic workload and planning and strategies for learning assessment were correlated $(\beta=0.28 ; p=0.003)$ and the inverse academic workload was associated with academic achievement $(\beta=0.23 ; p=0.010)$.

Overall the model suggests that academic achievement during the first year of medical school is dependent on exposure to motivation, self-directedness, and inverse academic workload, during secondary and medical school, and previous academic achievement (see Fig. 1).

\section{Discussion}

The main purpose of the present study was to extend prior cross-sectional research and evaluate prospectively how the SRLS and academic workload relate to academic achievement across the secondary school to medical school transition.

First, it is important to note that, according to the exploratory factor analysis, two patterns of academic workload were identified in both secondary school and medical school, wherein students with a high subjective workload also demonstrated high time devoted to study (tandem academic workload) and those who devoted a significant amount of time to study had a low subjective workload (inverse academic workload). These patterns of study are interesting because study time and subjective workload are generally described separately. Our study shows that it is important to evaluate the interaction between these two variables, and the path analysis showed that only the inverse relationship positively affected academic achievement among medical students, whether in secondary school or medical school, i.e., study time only predicts academic achievement if students perceive an appropriate workload. In their research involving first-year learners from several faculties at the University of Ulster, Lowe and Cook reported that a third of students experienced difficulties in adapting to a more independent form of studying, struggled with workloads, and had trouble taking responsibility for their learning (Lowe and Cook 2003). Managing study time is a challenge for students (Van der Meer et al. 2010); however, doing so effectively at the secondary level and during the first-year of medical school, while also effectively adapting to different workloads, can improve achievement. Supportive teacherstudent relationships, formative assessment and clear objectives, are some of the strategies that can be used to reduce the students overload (Kember 2004).

We found that prior SRLS are associated with later academic workload. Our results indicate an effect of (prior) self-directedness on (later) tandem academic workload. This implies that students who are self-directed at the secondary level are likely to feel less overwhelmed by the workload demands of the medical course. However, as hypothesized, this relationship had no effect on academic achievement at first year medical school. It is possible, therefore, that this association would be significant when evaluated in the next curricular years. Moreover, the longitudinal model findings revealed 
that academic workload was not a predictor of SRLS. This result may be explained by the fact that secondary students are adapted to a structure in which these skills are not necessary.

This study has also showed that SRLS are associated with academic achievement i.e., motivation and action to learn and self-directedness had significant direct and indirect effects on academic achievement in the first year of medical school. It is somewhat surprising that despite a positive indirect effect, the motivation and action to learning at secondary school had a negative direct relationship with medical school academic achievement. This result suggests that motivation is a predictor of academic achievement when taking past and future measures of motivation into account. For instance, if two students have the same degree of motivation during the first year of medical school, the student who had greater motivation at the secondary level may have inferior results. In other words, decreased motivation from secondary school to medical school is a predictor of academic failure during first-year medical education. As mentioned in the literature review, individuals with a motivated orientation tend to have higher levels of achievement, owing to their persistent use of cognitive strategies (Pintrich and De Groot 1990). However, in the same way that motivation has an impact on academic achievement, it is also affected by factors such as curriculum structure and/or learning environment (Kusurkar et al. 2011a, b). This may explain why some research concerning medical schools either (a) suggests an indirect association between motivation and academic achievement mediated by study efforts and the use of effective study strategies (Wilkinson et al. 2007), or (b) fails to reveal an association between motivation and academic success (Popovic 2010; Luqman 2013). It is important, but beyond the scope of this research, to determine what type of motivation may affect motivational strength during the first year of medical school. We believe that part of this decreased motivation is due to the emphasis that most students place on subjects such as anatomy, histology, and physiology, integrated into morphophysiology, which also contribute to lower grades. Students still have limited knowledge of the human body and are young and inexperienced to deal with the complexity of the discipline and the new higher education learning environment (Arantes et al. 2017). Additionally, students could have higher expectations in the beginning of the year, which then leads to lowered motivation.

Another important finding was the relationship between self-directedness and academic achievement in medical school and that prior self-directedness had an indirect effect on academic achievement in medical school via its direct effect on self-directedness in medical school. In the present study, self-directedness was linked to autonomy and taking responsibility for learning. In general, secondary education is largely teacher-centred and higher education requires greater regulation (Demirören et al. 2016). In fact, we found no association between self-directedness and academic achievement at the secondary level. Thereby, our results support the premise that self-directed learners exist at the secondary level and that those who take responsibility for their learning will likely have a greater academic success during their first-year of medical school. Indeed, medical students who are diverse in their orientation and seek autonomy are more likely to pursue a strategy of self-directed learning (Fox and West 1984).

In addition to the aforementioned findings, it should also be mentioned that students who perceived a high workload during secondary school indicated that they were more likely to adopt planning and strategies for learning assessment. Even though these played a facilitative role in learning, students should become better self-regulated learners if these are adopted during a medical course (Van Den Hurk et al. 1999). However, at the secondary level, this may lead to inefficient time allocation and an increase in the perceived workload. 
Despite the aforementioned discoveries, this study has several limitations that ought to be noted. First, it was limited to a single institution; hence, caution should be taken while attempting to generalise the results to other courses. Second, the assessment was dependent on the subjective experiences of the respondents which may lead to recall biases. Third, the current study reports the exploratory factor analysis, particularly for SRLPS, from a relatively small sample size. Nevertheless, later studies showed similar factors. Notwithstanding these limitations, the study offers significant new knowledge and insights concerning academic achievement during the educational transition from secondary to medical school. For medical students at the secondary level, academic achievement depends solely on study time without overload; however, in medical school, prior academic achievement as well study time without overload motivated students to partake in more self-directed learning, which increased their likelihood of experiencing academic success. Developing an awareness of these issues among teachers may be a crucial first step in creating learning environments that enable medical students to become skilled lifelong learners, capable of managing their time efficiently and, by extension, overcoming work overload. Based on our results some areas of intervention can be identified. Promoting self-directedness should be the driving force during the first-year medical course, since it leads to successful study and a less overwhelming effect. Moreover, it is a way of helping to sustain students' motivation (Kusurkar et al. 2011b). Positive and constructive feedback, experiences of taking control and providing structured guidance are essential for the development of these skills (Kusurkar et al. 2011b). On the other hand, it is essential that teachers realize the pressures that individual students face, and estimating the prevalence of students in the identified patterns of linear and inverse VOLTE at the beginning of a course can alert teachers to this.

\section{Conclusion}

We found a significant relationship between prior self-directedness and later tandem academic workload. More importantly, this relationship does not predict academic achievement. This study demonstrated that success during the first year of medical school is dependent on exposure to motivation, self-directedness and higher study time without overload, during secondary school and medical school, and prior academic achievement. Additionally, the interaction between what students are during secondary school and medical school is a predictor of whether positive outcomes will be obtained in medical school, as well as the likelihood that they will be capable of coping with the rigors of a medical course.

Student-centered learning can mean different approaches (such as project-based learning, team-based learning or case-based learning); nevertheless, all of them have the same core goal: to motivate students and to foster lifelong skills through active engagement. Managing effective study time and self-regulated learning are necessary skills to become a successful life-long learner. The insights gained from this study may be of assistance to other medical school curriculums and provides a baseline against which changes in SRLS and academic workload in following curricular years are monitored and the effect of these changes on academic achievement during medical studies is assessed.

\section{Appendix 1}

See Table 3. 
Table 3 Exploratory factor analysis for AWS and NASA-TLX

\begin{tabular}{lrr}
\hline Items & T1 & T2 \\
& Factor & Factor \\
\hline AWS & 0.744 & 0.745 \\
The workload was too heavy & 0.672 & 0.740 \\
It seems to me that the syllabus tries to cover too many topics & -0.513 & -0.552 \\
It was generally given enough time to understand the things I had to learn & 0.510 & 0.746 \\
There was a lot of pressure on me to do this course & 0.642 & 0.813 \\
The sheer volume of work to be got through in this course meant it couldn't all & & 0.774 \\
$\quad$ be all comprehended & 0.834 & 0.516 \\
NASA-TLX & 0.400 & 0.701 \\
Mental demand & 0.749 & 0.219 \\
Physical demand & -0.329 & 0.604 \\
Time pressure & 0.726 & 0.716 \\
Performance level achieved & 0.649 & \\
Frustration experienced & & \\
Effort expended & & \\
\hline
\end{tabular}

\section{Appendix 2}

See Table 4.

Table 4 Exploratory factor analysis for perceived workload (NASA and AWS) and study time (class and assessment period)

\begin{tabular}{|c|c|c|c|c|}
\hline & \multirow{2}{*}{\multicolumn{2}{|c|}{$\frac{\text { Time } 1}{\text { Factor* }}$}} & \multirow{2}{*}{\multicolumn{2}{|c|}{$\frac{\text { Time } 2}{\text { Factor* }}$}} \\
\hline & & & & \\
\hline & 1 & 2 & 1 & 2 \\
\hline AWS & 0.71 & -0.51 & 0.73 & -0.40 \\
\hline NASA & 0.75 & -0.44 & 0.70 & -0.45 \\
\hline Study time at class period & 0.68 & 0.46 & 0.68 & 0.35 \\
\hline Study time at assessment period & 0.71 & 0.54 & 0.56 & 0.67 \\
\hline$\%$ Variance explained (\%) & 51 & 24 & 45 & 23 \\
\hline
\end{tabular}

*Only factor loading $>0.30$ are shown

\section{Appendix 3}

See Table 5. 


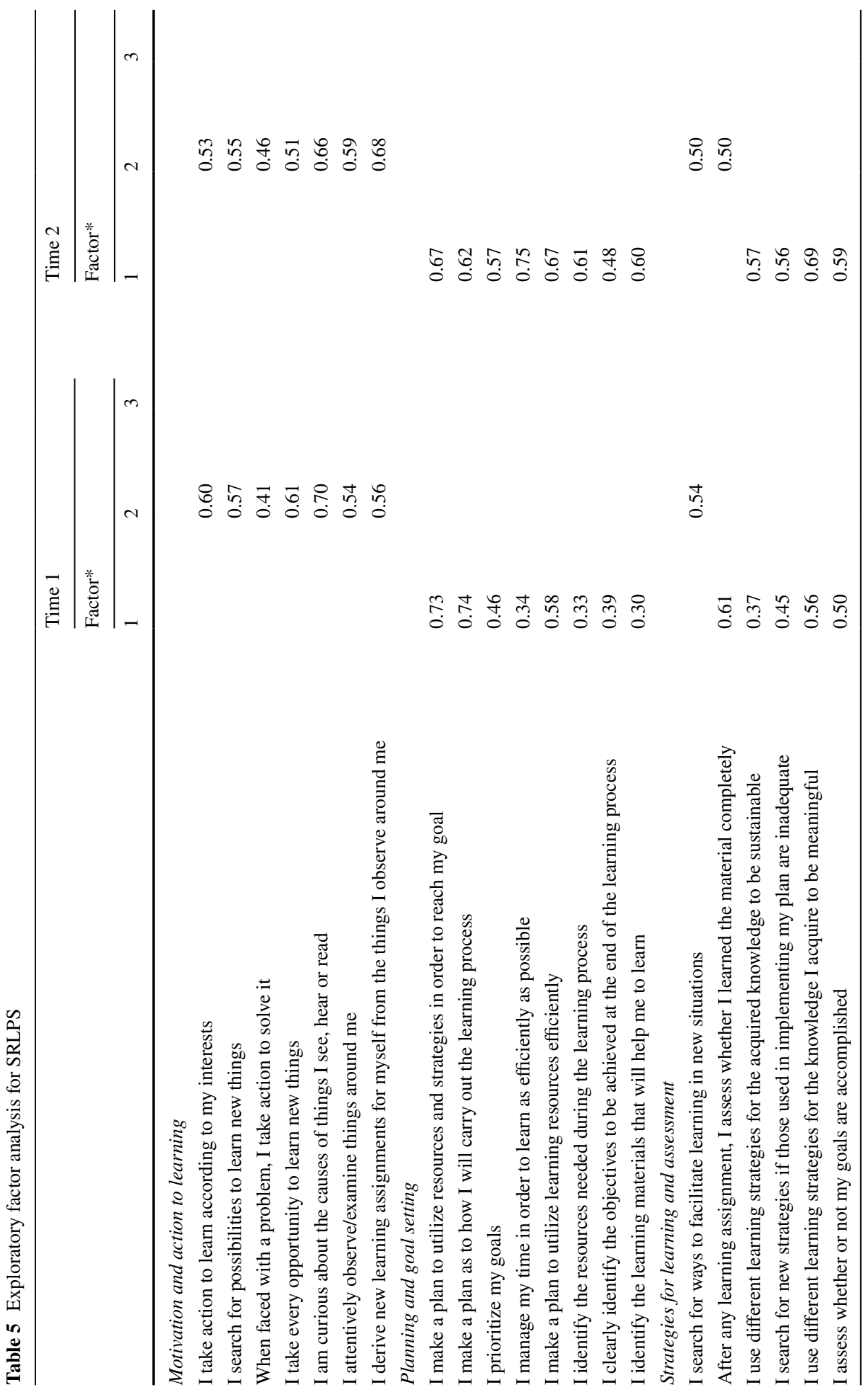




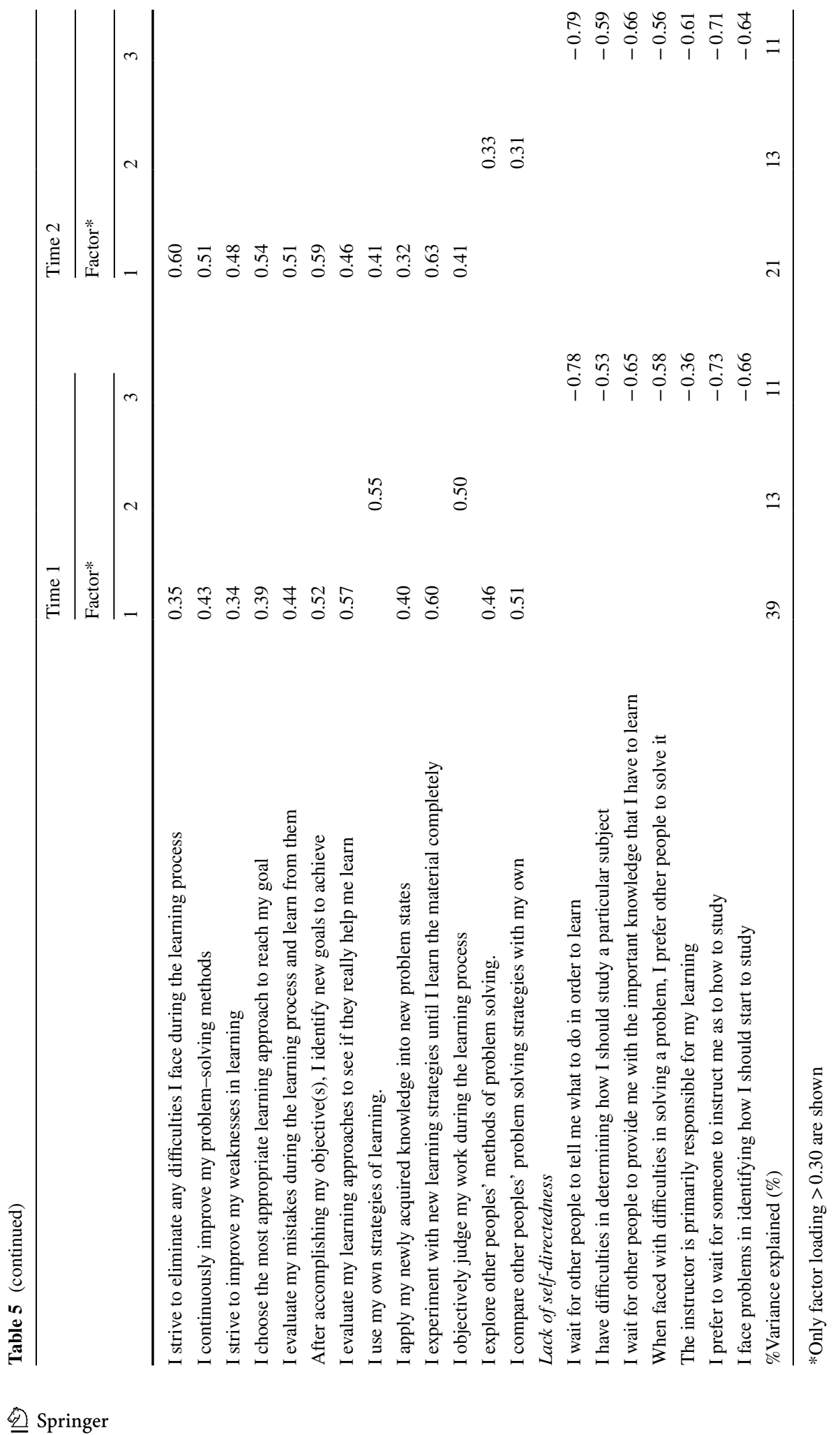




\section{References}

Arantes, M., Barbosa, J., \& Ferreira, M. A. (2017). Differences in the students' perceptions on the teaching of neuroanatomy in a medical curriculum organized by disciplines and an integrated medical curriculum. Acta Médica Portuguesa, 30(1), 26-33.

Artino, A. R., Jr., Dong, T., DeZee, K. J., Gilliland, W. R., Waechter, D. M., et al. (2012). Achievement goal structures and self-regulated learning: Relationships and changes in medical school. Academic Medicine, 87(10), 1375-1381.

Atalay, K. D., Can, G. F., Erdem, S. R., \& Müderrisoglu, I. H. (2016). Assessment of mental workload and academic motivation in medical students. JPMA. The Journal of the Pakistan Medical Association, 66(5), 574-578.

Barbosa, J., Silva, Á., Ferreira, M. A., \& Severo, M. (2016). Transition from secondary school to medical school: the role of self-study and self-regulated learning skills in freshman Burnout. Acta Médica Portuguesa, 29(12), 803-808.

Bentler, P. M. (1990). Comparative fit indexes in structural models. Psychological Bulletin, 107(2), 238.

Beyers, J., Bittner, A., Jr., \& Hills, S. (1989). 'Traditional and raw task load index (TLX) correlations: are paired comparisons necessary: Advances in Industrial Ergonomics and Safety I. London: Taylor and Francis.

Brint, S., \& Cantwell, A. M. (2010). Undergraduate time use and academic outcomes: Results from the University of California Undergraduate Experience Survey 2006. Teachers College Record, 112(9), 2441-2470.

Carroll, J. B. (1963). A model of school learning. Teachers College Record.

Costa, E. F. D. O., Santos, S. A., Santos, A. T. R. D. A., Melo, E. V. D., \& Andrade, T. M. D. (2012). Burnout syndrome and associated factors among medical students: a cross-sectional study. Clinics, 67(6), 573-580.

Demirören, M., Turan, S. \& Öztuna, D. (2016). Medical students' self-efficacy in problem-based learning and its relationship with self-regulated learning. Medical Education Online, 21.

Devlin, M., \& Gray, K. (2007). In their own words: A qualitative study of the reasons Australian university students plagiarize. High Education Research \& Development, 26(2), 181-198.

Enders, C. K. (2010). Applied missing data analysis. NY: Guilford Press.

Fox, R. D., \& West, R. F. (1984). Medical students' strategies for self-directed learning. Möbius: A Journal for Continuing Education Professionals in Health Sciences, 4(2), 20-26.

Gomathi, K. G., Ahmed, S., \& Sreedharan, J. (2012). Psychological health of first-year health professional students in a medical university in the United Arab Emirates. Sultan Qaboos University Medical Journal, 12(2), 206.

Guthrie, E., Black, D., Shaw, C., Hamilton, J., Creed, F., et al. (1995). Embarking upon a medical career: Psychological morbidity in first year medical students. Medical Education, 29(5), 337-341.

Hu, L. T., \& Bentler, P. M. (1999). Cutoff criteria for fit indexes in covariance structure analysis: Conventional criteria versus new alternatives. Structural Equation Modeling: A Multidisciplinary Journal, 6(1), 1-55.

Jacobs, S. R., \& Dodd, D. (2003). Student burnout as a function of personality, social support, and workload. Journal of College Student Development, 44(3), 291-303.

Jouhari, Z., Haghani, F. \& Changiz, T. (2015). Factors affecting self-regulated learning in medical students: A qualitative study. Medical Education Online, 20.

Karjalainen, A., Alha, K. \& Jutila, S. (2006). Give me time to think: Determining student workload in higher education. University of Oulu, Teaching Development Unit.

Kassab, S. E., Al-Shafei, A. I., Salem, A. H., \& Otoom, S. (2015). Relationships between the quality of blended learning experience, self-regulated learning, and academic achievement of medical students: a path analysis. Advances in Medical Education and Practice, 6, 27.

Kember, D. (2004). Interpreting student workload and the factors which shape students' perceptions of their workload. Studies in Higher Education, 29(2), 165-184.

Kerdijk, W., Cohen-Schotanus, J., Mulder, B., Muntinghe, F. L., \& Tio, R. A. (2015). Cumulative versus end-of-course assessment: Effects on self-study time and test performance. Medical Education, 49(7), 709-716.

Krause, K. L., \& Coates, H. (2008). Students' engagement in first-year university. Assessment \& Evaluation in Higher Education, 33(5), 493-505.

Kurata, Y. B., Bano, R. M. L. P., \& Matias, A. C. (2015). Effects of workload on academic performance among working students in an undergraduate engineering program. Procedia Manufacturing, 3, 3360-3367. 
Kusurkar, R. A., Croiset, G., \& Ten Cate, O. T. J. (2011a). Twelve tips to stimulate intrinsic motivation in students through autonomy-supportive classroom teaching derived from self-determination theory. Medical Teacher, 33(12), 978-982.

Kusurkar, R., Ten Cate, T. J., Van Asperen, M., \& Croiset, G. (2011b). Motivation as an independent and a dependent variable in medical education: A review of the literature. Medical Teacher, 33(5), e242-e262.

Kyndt, E., Dochy, F., Struyven, K., \& Cascallar, E. (2011). The perception of workload and task complexity and its influence on students' approaches to learning: A study in higher education. European Journal of Psychology of Education, 26(3), 393-415.

Lowe, H., \& Cook, A. (2003). Mind the gap: are students prepared for higher education? Journal of Further and Higher Education, 27(1), 53-76.

Luqman, M. (2013). Relationship of academic success of medical students with motivation and pre-admission grades. Journal of the College of Physicians and Surgeons Pakistan, 23, 31-36.

Mehdinezhad, V. (2011). First year students' engagement at the university. International Online Journal of Educational Sciences, 3(1), 47-66.

Pintrich, P. R., \& De Groot, E. V. (1990). Motivational and self-regulated learning components of classroom academic performance. Journal of Educational Psychology, 82(1), 33.

Popovic, C. (2010). Myth busting: an examination of teachers' beliefs about first-year medical students. How well do teachers know their students? Innovations in Education and Teaching International, 47(2), 141-154.

Ramsden, P. (1991). A performance indicator of teaching quality in higher education: The course experience Questionnaire. Studies in Higher Education, 16(2), 129-150.

Revelle, W., \& Zinbarg, R. E. (2009). Coefficients alpha, beta, omega, and the glb: Comments on Sijtsma. Psychometrika, 74(1), 145.

Sandars, J., \& Cleary, T. J. (2011). Self-regulation theory: Applications to medical education: AMEE Guide No. 58. Medical Teacher, 33(11), 875-886.

Schmidt, H. G., Cohen-Schotanus, J., van der Molen, H. T., Splinter, T. A., Bulte, J., et al. (2010). Learning more by being taught less: A "time-for-self-study" theory explaining curricular effects on graduation rate and study duration. Higher Education, 60(3), 287-300.

Smith, C. K., Peterson, D. F., Degenhardt, B. F., \& Johnson, J. C. (2007). Depression, anxiety, and perceived hassles among entering medical students. Psychology, Health \& Medicine, 12(1), 31-39.

Torenbeek, M., Jansen, E., \& Hofman, A. (2010). The effect of the fit between secondary and university education on first-year student achievement. Studies in Higher Education, 35(6), 659-675.

Turan, S., Demirel, Ö., \& Sayek, İ. (2009). Metacognitive awareness and self-regulated learning skills of medical students in different medical curricula. Medical Teacher, 31(10), e477-e483.

Van Den Hurk, M. M., Wolfhagen, I. H., Dolmans, D. H., \& Van Der Vleuten, C. P. (1999). The impact of student-generated learning issues on individual study time and academic achievement. Medical Education, 33(11), 808-814.

Van der Meer, J., Jansen, E., \& Torenbeek, M. (2010). 'It's almost a mindset that teachers need to change': First-year students' need to be inducted into time management. Studies in Higher Education, 35(7), $777-791$.

West, C., \& Sadoski, M. (2011). Do study strategies predict academic performance in medical school? Medical Education, 45(7), 696-703.

Wilkinson, T. J., Wells, J. E., \& Bushnell, J. A. (2007). Medical student characteristics associated with time in study: Is spending more time always a good thing? Medical Teacher, 29(2-3), 106-110.

Zimmerman, B. J. (1989). A social cognitive view of self-regulated academic learning. Journal of Educational Psychology, 81(3), 329.

Zimmerman, B. J. (2002). Becoming a self-regulated learner: An overview. Theory into Practice, 41(2), 64-70.

Zimmerman, B. J., \& Schunk, D. H. (2001). Self-regulated learning and academic achievement: Theoretical perspectives. London: Routledge.

Zimmerman, B. J. \& Schunk, D. H. (2008). An essential dimension of self-regulated learning. Motivation and self-regulated learning: theory, research, and applications, 1. 